\title{
A study on the dyeing of sodium hydroxide treated polyester / cotton blend fabrics
}

\author{
Jeyakodi Moses J., Pitchai S. \\ Department of Applied Science, PSG College of Technology, Coimbatore 641004, Tamil Nadu, India \\ Email address: \\ jj_moses2k2@yahoo.co.in (Jeyakodi M. J.)
}

\section{To cite this article:}

Jeyakodi Moses J., Pitchai S.. A Study on the Dyeing of Sodium Hydroxide Treated Polyester / Cotton Blend Fabrics. International Journal of Science, Technology and Society. Special Issue: Technology Transfer. Vol. 3, No. 1-1, 2015, pp. 1-9. doi: 10.11648/j.ijsts.s.2015030101.11

\begin{abstract}
The polyester (100\%), cotton (100\%) and Polyester / Cotton blend fabrics (65/35; 50 / 50 \& 35 / 65) were treated with sodium hydroxide followed by hydrophilic finishing and dyeing to impart hygroscopic and dyeing characteristics. Then the finished fabric was tested for $\mathrm{k} / \mathrm{s}$ value, fastness properties, wetting behaviour, water retention, wicking behaviour and static charge respectively. The sodium hydroxide treated and hydrophilic finished fabrics show improved $\mathrm{k} / \mathrm{s}$ value with good fastness properties (wash, light and rubbing), wetting, water retention and wicking behaviour that consequently leads for the reduction of static charge. The Polyester / Cotton blend fabrics after sodium hydroxide treatment and hydrophilic finishing showed very good improvement in these characteristics.
\end{abstract}

Keywords: Hydrophilic Finish, k/s Value, Fastness Properties, Wetting, Wicking

\section{Introduction}

Poly (ethylene terephthalate) (PET) fibers are widely used in production of garments because of their low production cost and good fiber properties [1]. Inherently hydrophobic polyester fabric lacks to provide the comfort feel and also has the tendency to accumulate static charge. PET fiber possesses a high zeta potential value of around $52 \mathrm{mV}$ [2]. Alkaline finishing of polyester fabric with sodium hydroxide changes fabric weight, strength, wettability and aesthetics [3]. The surface hydrolysis of PET fiber material generates additional hydroxyl groups and carboxyl groups on the surface. Another important method used to modify surface properties of polyester fabric, is by treatment with hydrophilic polymers [4]. According to the mechanism of alkali hydrolysis of PET surface proposed by Sanders and Zeronian (1982), the hydroxide ion attacks the electron deficient carboxyl carbon, resulting in the production of hydroxyl and carboxyl end groups [5]. The structural macromolecular parameters of normal and alkali treated polyester fibers were determined [6] by $\mathrm{x}$-ray diffraction and thermal analysis.

Polyester / cotton blend ( $\mathrm{P} / \mathrm{C}$ blend) enters in market because it has the advantages of both PET and cotton (cellulose) and can be wearable [7]. A fabric made from a $\mathrm{P} / \mathrm{C}$ blend combines the strengths of the two fibers, like breathability, tear-resistant, and can be fashioned into abrasion-resistant garments. In the present study the Polyester / Cotton blend fabrics (65 / 35; 50 / 50 \& 35 / 65) were treated with sodium hydroxide followed by hydrophilic finish to impart hydrophilic characteristics. The treated fabrics were dyed using basic dye, reactive dye and disperse dye and studied for $\mathrm{k} / \mathrm{s}$ value, fastness properties, static charge, wetting behaviour, water retention, and wicking behaviour.

\section{Experimental}

\subsection{Materials}

I) The materials used in this study were as mentioned in the following Table (i); 
Table (i). Details of the polyester, cotton and polyester / cotton blend fabrics

\begin{tabular}{|c|c|c|c|c|}
\hline S. No. & Textile Materials & Proportion & Details & \\
\hline 1 & Cotton fabric & $100 \%$ (gsm: 71 , cover factor: 18.08 ) & $\begin{array}{l}\text { Warp } \\
\text { Weft }\end{array}$ & $\begin{array}{l}\text { Ends/inch: } 98 \\
\text { Picks/inch: } 78 \\
\text { Count: } 60 \text { (warp \& weft) }\end{array}$ \\
\hline 2 & Polyester fabric & $100 \%$ (gsm: 68 , cover factor: 15.83 ) & $\begin{array}{l}\text { Warp } \\
\text { Weft }\end{array}$ & $\begin{array}{l}\text { Ends/inch: } 92 \\
\text { Picks/inch: } 80 \\
\text { Count: } 85 \text { (warp \& weft) }\end{array}$ \\
\hline \multirow{3}{*}{3} & \multirow{3}{*}{$\begin{array}{l}\text { Polyester / Cotton }(\mathrm{P} / \mathrm{C}) \\
\text { blended fabric }\end{array}$} & I) 65 / 35 (gsm: 66, Cover factor: 16.36 & $\begin{array}{l}\text { Warp } \\
\text { Weft }\end{array}$ & $\begin{array}{l}\text { I) Ends/inch: } 94 \\
\text { Picks/inch: } 79 \\
\text { Count: } 80 \text { (warp \& weft) }\end{array}$ \\
\hline & & II) 50 / 50 (gsm: 66, Cover factor: 17.22) & $\begin{array}{l}\text { Warp } \\
\text { Weft }\end{array}$ & $\begin{array}{l}\text { II) Ends/inch: } 95 \\
\text { Picks/inch: } 78 \\
\text { Count: } 72 \text { (warp \& weft) }\end{array}$ \\
\hline & & III) 35 / 65 (gsm: 68 , cover factor: 17.85 ) & $\begin{array}{l}\text { Warp } \\
\text { Weft }\end{array}$ & $\begin{array}{l}\text { III) Ends/inch: } 94 \\
\text { Picks/inch: } 70 \\
\text { Count: } 66 \text { (warp \& weft) }\end{array}$ \\
\hline
\end{tabular}

1) Chemicals and auxiliaries:

Fatty alcohol, ethylene oxide, and propylene oxide (supplied by Merck Specialities Pvt Ltd, India); hydrochloric acid, sodium hydroxide, glacial acetic acid, magnesium chloride, sodium lauryl sulphate, and sodium carbonate mentioned elsewhere in this study were of analytical grade. Commercial dyes such as Para-rosaniline hydrochloride (basic dye) (colour index number-42500), Tulactive E (reactive dye) (colour index number-reactive red 141) and Dianix Navy S2G (disperse dye) (Colour index numberdisperse blue 79) were used for dyeing the polyester, cotton and $\mathrm{P} / \mathrm{C}$ fabrics.

\subsection{Methods}

\subsubsection{Pretreatment of Polyester, Cotton and P / C Fabrics}

The $100 \%$ PET fabric and $100 \%$ cotton fabric were pretreated ((desizing for PET fabric using $8 \mathrm{gpl}_{2} \mathrm{SO}_{4}$ for 60 minutes at ambient temperature); and desizing (10 gpl $\mathrm{HCl}$, 60 minutes, $\left.40^{\circ} \mathrm{C}\right)$, scouring $(2 \% \mathrm{NaOH}$ (owm) \& $1 \%$ $\left.\mathrm{Na}_{2} \mathrm{CO}_{3}(\mathrm{owm})\right)$, and peroxide bleaching $\left(2 \% \mathrm{H}_{2} \mathrm{O}_{2}\right.$ (owm), $1 \% \mathrm{Na}_{2} \mathrm{CO}_{3}$ (owm) \& $0.5 \%$ wetting agent (owm)) for cotton fabric) by the established technique mentioned earlier $[3,8$, 9]. Polyester / cotton blended (P / C 65 / 35; P / C 50 / 50; \& $\mathrm{P} / \mathrm{C} 35$ / 65) fabric was immersed in $10 \mathrm{gpl}$ hydrochloric acid at $40^{\circ} \mathrm{C}$ and treated for one hour at the same temperature with material to liquor ratio $1: 50$, to get rid of the added impurities [8], followed by mild hydrogen peroxide $(0.5 \%$ owm) bleaching [9].

\subsubsection{Treatment of Sodium Hydroxide on Polyester, Cotton and $P$ / C Fabrics}

The pretreated fabrics (P/C blend fabrics, $100 \%$ cotton \& PET fabrics) were treated with sodium hydroxide (concentration: $4 \%$ owm; Temperature: around $100^{\circ} \mathrm{C}$; and time: one hour), followed by neutralization, washing and drying [10].

\subsubsection{Application of Hydrophilic Finish on Sodium Hydroxide Treated Polyester, Cotton and P / C Fabrics}

The sodium hydroxide treated fabrics were then treated with a mixture of equal proportion of ethoxylated alcohol consisting of fatty alcohol, ethylene oxide, and propylene oxide (hydrophilic finish) of concentration $0.5 \%, 1.0 \%, 1.5 \%$, $2 \%$ and $2.5 \%(\mathrm{w} / \mathrm{v})$ respectively for forty minutes at $75^{\circ} \mathrm{C}$ followed by curing at $140^{\circ} \mathrm{C}$ for 90 seconds.

\subsubsection{Dyeing of Polyester, Cotton and P/C Fabrics}

\subsubsection{Dyeing of Polyester, Cotton and P / C Fabrics Using Basic Dye}

The hydrophilic finished sodium hydroxide treated fabrics were dyed with basic dye of $2 \%$ owm (Para rosaniline hydrochloride), mlr 1:100 at boil with $\mathrm{pH} 9$ (sodium hydroxide). The dyed samples were washed with hot water, soaped and dried [11].

\subsubsection{Dyeing of Polyester, Cotton and P / C Fabrics Using Reactive Dye}

The hydrophilic finished sodium hydroxide treated fabrics were dyed using reactive dye of $2 \%$ owm (Tulactive $-E$ ) with MLR 1:50. The samples were immersed in the dye bath and worked for 10 minutes. The temperature was gradually raised to $60^{\circ}$ to $80^{\circ} \mathrm{C}$. Then in two stages, with an interval of 10 minutes previously dissolved sodium sulphate (exhausting agent, $80 \mathrm{~g} / \mathrm{l}$ ) was added to the dyebath. After 20 minutes previously dissolved sodium hydroxide (fixing agent, $23 \mathrm{~g} / \mathrm{l}$ ) was added in two installments with an interval of 20 minutes and dyeing continued for further 45 minutes at $80^{\circ} \mathrm{C}$. The dyed samples were washed with cold running water and then soaped $[9,12]$.

\subsubsection{Dyeing of Polyester, Cotton and P / C Fabrics Using Disperse Dye}

The hydrophilic finished sodium hydroxide treated fabrics were dyed with disperse dye of $2 \%$ owm (dianix navy S2G) and $1 \mathrm{~g} / \mathrm{l}$ dispersing agent in a HTHP dyeing machine (Ahiba Polymat). The dyeing was carried out at $130^{\circ} \mathrm{C}$ and at $\mathrm{pH} 5$ (set by acetic acid). The dyed samples were washed with hot water, soaped and dried $[9,12]$.

\subsubsection{Measurement of $K / S$ Value on Dyed Polyester, Cotton and $P$ / C Fabrics}

Colour intensities of the dyed hydrophilic finished sodium hydroxide treated fabrics were measured using 
spectrophotometer (model: Premier colour scan ss 5000 A) within the range of 400-700 $\mathrm{nm}$. Reflectance values were measured and the relative colour strength $(\mathrm{K} / \mathrm{S})$ was calculated using Kubelka Munk equation [13]. (K/S) defines a relationship between spectral reflectance $(\mathrm{R})$ of sample and its absorption $(\mathrm{K})$ and scattering $(\mathrm{S})$ characteristics. $\mathrm{K} / \mathrm{S}=$ $\left\{(1-\mathrm{R})^{2} / 2 \mathrm{R}\right\}$.

\subsubsection{Colour Fastness Test on Dyed Polyester, Cotton and P / C Fabrics}

Colour fastness of the dyed hydrophilic finished sodium hydroxide treated to washing, light and rubbing were determined by standard test methods. The results were assessed in ratings from grade 1 (very poor) to grade 5 (excellent). The colour change was assessed according to grey scale from grade 1 (much altered) to grade 5 (unaltered).

\subsubsection{Wash Fastness on Dyed Polyester, Cotton and P / C Fabrics}

The wash fastness of the dyed hydrophilic finished sodium hydroxide treated fabrics was determined by IS 764-test 3 method [14]. The fabrics $(10 \times 4 \mathrm{~cm})$ was sewed along all four edges with same size of multifibre fabric. The composite specimen was washed at $60^{\circ} \mathrm{C}$ for 30 minutes using detergent solution $5 \mathrm{~g} / \mathrm{l}$ maintaining fabric to liquor ratio at $1: 50$. The change in colour of the specimen and staining of the adjacent fabric were assessed by grey scale.

\subsubsection{Light Fastness on Dyed Polyester, Cotton and P / C Fabrics}

The light fastness of the dyed hydrophilic finished sodium hydroxide treated fabrics were determined by AATCC test method 16E-2004 [15]. These dyed fabrics were exposed separately for 10 hours under artificial light source- xenon arc lamp. The colour change of exposed portion was compared with masked portion of test specimen.

\subsubsection{Fastness to Rubbing on Dyed Polyester, Cotton and $P$ / C Fabrics}

Colour fastness to crocking was determined by AATCC test method 8-2007 [16]. AATCC standardized crockmeter was used to determine the rubbing fastness of dyed fabrics under wet and dry conditions to assess the staining property.

\subsubsection{Wetting Behaviour of Hydrophilic Finished Sodium Hydroxide Treated Polyester, Cotton and P / C Fabrics}

Wettability is the time taken for a water drop to penetrate into the hydrophilic finished sodium hydroxide treated fabrics. The wettability of hydrophilic finished sodium hydroxide treated fabrics was determined as per AATCC test method 79 [17].

\subsubsection{Water Retention in Hydrophilic Finished Sodium Hydroxide Treated Polyester, Cotton and P / C Fabrics}

Absorption capacity of hydrophilic finished sodium hydroxide treated fabrics was measured by standard AATCC 21-1978 test method [18].

\subsubsection{Wicking Behaviour of Hydrophilic Finished Sodium Hydroxide Treated Polyester, Cotton and P / C Fabrics}

The wicking height of the hydrophilic finished sodium hydroxide treated fabrics, both in warp and weft directions was determined [19]. Fabric samples measuring $10 \mathrm{~cm}$ x 2.5 $\mathrm{cm}$ were taken. Each of the sample pieces was clamped to a scale and held at a position such that the tip of the sample just touched the water taken in a beaker. $1 \%$ reactive dye (Prussian blue) was added for tracking the movement of water. The height of water reached after five minutes was measured [20].

\subsubsection{Measurement of Static Charge on Hydrophilic Finished Sodium Hydroxide Treated Polyester, Cotton and P / C Fabrics}

The static charge of the hydrophilic finished sodium hydroxide treated fabrics was measured using a digital multimeter, WIRA- Meech 983 V2 Static Locator.

\section{Results and Discussion}

\subsection{Dyeing of Polyester, Cotton and P / C Fabrics}

\subsubsection{Dyeing of Polyester, Cotton and P/C Fabrics with Basic Dye}

The hydrophilic finished sodium hydroxide treated fabrics were dyed using basic dye para-rosaniline hydrochloride, and the K/S values obtained are given in Table 1-a. The basic dye binds well with carboxylic group present in the sodium hydroxide treated polyester blended textile fabric [21]. K/S value can be taken as the indication of the amount of carboxylic groups present in these fabrics. Obviously the cotton fabric showed the highest $\mathrm{K} / \mathrm{S}$ value due to the improved dye uptake by the reaction between basic dye and the high reactive groups in the fabric [22]. The sodium hydroxide treated and hydrophilic finished PET fabric with more cotton portion give good dye uptake compared with those of the polyester fabric. There is a remarkable improvement in the dye uptake on polyester fabric also due to the sodium hydroxide treatment and hydrophilic finishing.

\subsubsection{Dyeing of Polyester, Cotton and P/C Fabrics with Reactive Dye}

The hydrophilic finished sodium hydroxide treated fabrics were dyed using a reactive dye and the $\mathrm{K} / \mathrm{S}$ values are given in Table 1-b. Similar to the basic dye, reactive dye also shows improved dye uptake on the sodium hydroxide treated and hydrophilic finished fabrics. The cotton fabric showed the highest $\mathrm{K} / \mathrm{S}$ value due to the improved dye uptake by the reaction between reactive dye and the high reactive groups in the fabric. The sodium hydroxide treated and hydrophilic finished PET fabric with more cotton portion gives more dye uptake compared with those of the $100 \%$ polyester fabric. The $100 \%$ polyester fabric also shows good improvement in dye uptake after sodium hydroxide treatment and hydrophilic finishing. 


\subsubsection{Dyeing of Polyester, Cotton and P / C Fabrics with Disperse Dye}

The hydrophilic finished sodium hydroxide treated fabrics were dyed using dianix navy S2G (disperse dye) and the K/S values are given in Table 1-c. From this table, it is evident that the sodium hydroxide treated and hydrophilic finished cotton fabric does not show any increase in $\mathrm{K} / \mathrm{S}$ value compared to those of $100 \%$ PET fabric. The sodium hydroxide treated and hydrophilic finished $\mathrm{P} / \mathrm{C}$ blend fabric with more PET portion gives remarkable increase of dye uptake compared with those of the $100 \%$ cotton fabric. The dye uptake on $100 \%$ polyester fabric is also improved due to the sodium hydroxide treatment and hydrophilic finishing.

Table 1-a. K/S value of the basic dyed polyester, cotton and P / C fabrics

\begin{tabular}{|c|c|c|c|c|c|c|}
\hline \multirow{2}{*}{ S. No. } & \multirow{2}{*}{$\begin{array}{l}\text { Concentration of } \\
\text { hydrophilic finish (w/v) }\end{array}$} & \multicolumn{5}{|c|}{$\mathrm{K} / \mathrm{S}$ value $(550 \mathrm{~nm})$} \\
\hline & & Polyester & PC $65 / 35$ & $\mathrm{P} / \mathrm{C} \mathbf{5 0} / \mathbf{5 0}$ & P/C 35 / 65 & Cotton \\
\hline 1 & 0 & 2.218 & 4.736 & 6.384 & 7.852 & 9.661 \\
\hline 2 & 0.5 & 4.356 & 6.173 & 7.724 & 8.124 & 10.227 \\
\hline 3 & 1.0 & 5.792 & 7.647 & 8.385 & 9.733 & 10.571 \\
\hline 4 & 1.5 & 6.383 & 8.715 & 9.368 & 10.646 & 11.822 \\
\hline 5 & 2.0 & 7.869 & 9.087 & 10.286 & 11.573 & 12.454 \\
\hline 6 & 2.5 & 7.927 & 9.745 & 10.751 & 11.774 & 12.935 \\
\hline
\end{tabular}

Table 1-b. K/S value of the reactive dyed polyester, cotton and $P$ / C fabrics

\begin{tabular}{|c|c|c|c|c|c|c|}
\hline \multirow{2}{*}{ S. No. } & \multirow{2}{*}{$\begin{array}{l}\text { Concentration of } \\
\text { hydrophilic finish (w/v) }\end{array}$} & \multicolumn{5}{|c|}{$\mathrm{K} / \mathrm{S}$ value $(530 \mathrm{~nm})$} \\
\hline & & Polyester & PC 65 / 35 & $\mathrm{P} / \mathrm{C} 50$ / 50 & P/C 35 / 65 & Cotton \\
\hline 1 & 0 & 0.771 & 5.143 & 6.465 & 7.924 & 10.252 \\
\hline 2 & 0.5 & 4.728 & 7.224 & 7.915 & 8.852 & 11.515 \\
\hline 3 & 1.0 & 6.215 & 8.438 & 9.141 & 9.976 & 12.463 \\
\hline 4 & 1.5 & 7.317 & 9.482 & 9.862 & 10.923 & 14.861 \\
\hline 5 & 2.0 & 8.642 & 9.991 & 10.563 & 11.884 & 16.484 \\
\hline 6 & 2.5 & 8.821 & 10.102 & 10.914 & 11.957 & 16.821 \\
\hline
\end{tabular}

Table 1-c. K/S value of the disperse dyed polyester, cotton and P / C fabrics

\begin{tabular}{|c|c|c|c|c|c|c|}
\hline \multirow{2}{*}{ S. No. } & \multirow{2}{*}{$\begin{array}{l}\text { Concentration of } \\
\text { hydrophilic finish }(w / v)\end{array}$} & \multicolumn{5}{|c|}{$\mathrm{K} / \mathrm{S}$ value (610nm) } \\
\hline & & Polyester & PC 65 / 35 & P/C 50 / 50 & P/C 35 / 65 & Cotton \\
\hline 1 & 0 & 0.464 & 0.357 & 0.326 & 0.275 & 0.225 \\
\hline 2 & 0.5 & 2.347 & 2.012 & 1.985 & 1.826 & 0.223 \\
\hline 3 & 1.0 & 4.516 & 3.875 & 3.248 & 3.087 & 0.218 \\
\hline 4 & 1.5 & 7.118 & 6.215 & 5.824 & 5.577 & 0.211 \\
\hline 5 & 2.0 & 8.172 & 7.526 & 6.922 & 6.783 & 0.208 \\
\hline 6 & 2.5 & 8.872 & 7.328 & 7.116 & 6.928 & 0.201 \\
\hline
\end{tabular}

\subsection{Wash Fastness on Dyed Polyester, Cotton and P / C Fabrics}

The data of wash fastness properties of the dyed (basic dye, reactive dye and disperse dye) hydrophilic finished sodium hydroxide treated fabrics are given in the Tables 2-a, 2-b and 2 -c respectively. As expected, the reactive dyed cotton fabric shows the maximum wash fastness value $(4 \& 4-5)$ which is followed by those of blended fabric (3 \& 3-4) with more cotton proportions. The basic dyed cotton fabric (2-3 \& 3) as well as cotton blended fabric with polyester ( 2 \& 2-3) show good wash fastness properties. The disperse dyed polyester fabric shows moderate wash fastness values (2-3) followed by the corresponding polyester/cotton blended fabric ( $2 \& 1$ 2 ). It is observed that the wash fastness properties of reactive dyed and basic dyed polyester fabrics as well as the disperse dyed cotton fabric only show very poor values (1 \& 1-2). There is a good improvement in the wash fastness properties of the blended fabric when dyed with basic dye, reactive dye, and disperse dye respectively. The sodium hydroxide treatment and hydrophilic finishing on polyester and its blend give remarkable improvement in the wash fastness properties in continuation of their good colour values. 
Table 2-a. Wash fastness of basic dyed polyester, cotton and P / C fabrics

\begin{tabular}{|c|c|c|c|c|c|c|}
\hline \multirow{2}{*}{ S. No. } & \multirow{2}{*}{$\begin{array}{l}\text { Concentration of } \\
\text { hydrophilic finish (w/v) }\end{array}$} & \multicolumn{5}{|c|}{$\mathrm{K} / \mathrm{S}$ value $(610 \mathrm{~nm})$} \\
\hline & & Polyester & PC $65 / 35$ & $\mathrm{P} / \mathrm{C} 50 / 50$ & $\mathrm{P} / \mathrm{C} 35$ / 65 & Cotton \\
\hline 1 & 0 & 1 & 1 & $1-2$ & $1-2$ & 2 \\
\hline 2 & 0.5 & 1 & $1-2$ & $1-2$ & $1-2$ & $2-3$ \\
\hline 3 & 1.0 & 1 & $1-2$ & $1-2$ & 2 & $2-3$ \\
\hline 4 & 1.5 & $1-2$ & $1-2$ & 2 & 2 & $2-3$ \\
\hline 5 & 2.0 & $1-2$ & $1-2$ & 2 & $2-3$ & 3 \\
\hline 6 & 2.5 & $1-2$ & 2 & 2 & $2-3$ & 3 \\
\hline
\end{tabular}

Table 2-b. Wash fastness of reactive dyed polyester, cotton and $P / C$ fabrics

\begin{tabular}{|c|c|c|c|c|c|c|}
\hline \multirow{2}{*}{ S. No. } & \multirow{2}{*}{$\begin{array}{l}\text { Concentration of } \\
\text { hydrophilic finish (w/v) }\end{array}$} & \multicolumn{5}{|c|}{$\mathrm{K} / \mathrm{S}$ value $(530 \mathrm{~nm})$} \\
\hline & & Polyester & PC 65 / 35 & $\mathrm{P} / \mathrm{C} 50 / 50$ & $\mathrm{P} / \mathrm{C} 35 / 65$ & Cotton \\
\hline 1 & 0 & 1 & 2 & $2-3$ & 3 & $3-4$ \\
\hline 2 & 0.5 & 1 & 2 & $2-3$ & 3 & $3-4$ \\
\hline 3 & 1.0 & $1-2$ & 2 & $2-3$ & $3-4$ & 4 \\
\hline 4 & 1.5 & $1-2$ & $2-3$ & 3 & $3-4$ & 4 \\
\hline 5 & 2.0 & $1-2$ & $2-3$ & 3 & 4 & $4-5$ \\
\hline 6 & 2.5 & 2 & 3 & 3 & 4 & $4-5$ \\
\hline
\end{tabular}

Table 2-c. Wash fastness of disperse dyed polyester, cotton and P / C fabrics

\begin{tabular}{|c|c|c|c|c|c|c|}
\hline \multirow{2}{*}{ S. No. } & \multirow{2}{*}{$\begin{array}{l}\text { Concentration of } \\
\text { hydrophilic finish (w/v) }\end{array}$} & \multicolumn{5}{|c|}{ Wash fastness } \\
\hline & & Polyester & PC 65 / 35 & $\mathrm{P} / \mathrm{C} 50 / 50$ & $\mathrm{P} / \mathrm{C} 35$ / 65 & Cotton \\
\hline 1 & 0 & 2 & 2 & $1-2$ & $1-2$ & 1 \\
\hline 2 & 0.5 & $2-3$ & 2 & $1-2$ & $1-2$ & 1 \\
\hline 3 & 1.0 & $2-3$ & 2 & $1-2$ & $1-2$ & 1 \\
\hline 4 & 1.5 & $2-3$ & 2 & $1-2$ & $1-2$ & 1 \\
\hline 5 & 2.0 & $2-3$ & 2 & $1-2$ & $1-2$ & 1 \\
\hline 6 & 2.5 & $2-3$ & 2 & $1-2$ & $1-2$ & 1 \\
\hline
\end{tabular}

\subsection{Light Fastness on Dyed Polyester, Cotton and P / C Fabrics}

The values of light fastness properties of the dyed (basic dye, reactive dye and disperse dye) hydrophilic finished sodium hydroxide treated fabrics are given in the Tables 3-a, $3-b$ and 3-c respectively. From these tables it is observed that the light fastness of reactive dyed cotton fabrics and its blend with polyester of more cotton proportion gives more light fastness followed by basic dyed fabric and disperse dyed fabrics. The sodium hydroxide treatment and hydrophilic finishing increase the light fastness properties of polyester, cotton and their blends when dyed with basic dye, reactive dye and disperse dye respectively. The disperse dyed polyester fabric shows moderate light fastness values (3) followed by the corresponding polyester/cotton blended fabric $(2-3 \& 2)$. The reactive dyed and basic dyed polyester fabrics as well as the disperse dyed cotton fabric only show very poor light fastness properties $(1 \& 1-2)$. There is a good improvement in the light fastness properties of the blended fabric when dyed with basic dye, reactive dye, and disperse dye respectively. The sodium hydroxide treatment and hydrophilic finishing on polyester and its blend give remarkable improvement in the light fastness properties after the corresponding dyeing.

Table 3-a. Light fastness of basic dyed polyester, cotton and P / C fabrics

\begin{tabular}{|c|c|c|c|c|c|c|}
\hline \multirow{2}{*}{ S. No. } & \multirow{2}{*}{$\begin{array}{l}\text { Concentration of } \\
\text { hydrophilic finish (w/v) }\end{array}$} & \multicolumn{5}{|c|}{$\mathrm{K} / \mathrm{S}$ value (610nm) } \\
\hline & & Polyester & PC 65 / 35 & $\mathrm{P} / \mathrm{C} \mathbf{5 0} / \mathbf{5 0}$ & $\mathrm{P} / \mathrm{C} 35 / 65$ & Cotton \\
\hline 1 & 0 & 1 & 2 & $2-3$ & 3 & $3-4$ \\
\hline 2 & 0.5 & $1-2$ & 2 & $2-3$ & 3 & 4 \\
\hline 3 & 1.0 & $1-2$ & 2 & 3 & 3 & 4 \\
\hline 4 & 1.5 & $1-2$ & 2 & 3 & $3-4$ & 4 \\
\hline 5 & 2.0 & 2 & $2-3$ & $3-4$ & $3-4$ & $4-5$ \\
\hline 6 & 2.5 & 2 & $2-3$ & $3-4$ & 4 & $4-5$ \\
\hline
\end{tabular}


Table 3-b. Light fastness of reactive dyed polyester, cotton and P / C fabrics

\begin{tabular}{llllll}
\hline \multirow{2}{*}{ S. No. } & $\begin{array}{l}\text { Concentration of } \\
\text { hydrophilic finish (w/v) }\end{array}$ & Kolyester & PC 65 / 35 & P/C 50 / 50 & P/C 35 / 65 \\
\cline { 3 - 6 } & 0 & $1-2$ & $2-3$ & 3 & $3-4$ \\
2 & 0.5 & $1-2$ & $2-3$ & 3 & $3-4$ \\
3 & 1.0 & 2 & $2-3$ & $3-4$ & 4 \\
4 & 1.5 & 2 & 3 & $3-4$ & 4 \\
5 & 2.0 & 2 & 3 & 4 & $4-5$ \\
6 & 2.5 & 2 & 3 & 4 & 5 \\
\hline
\end{tabular}

Table 3-c. Light fastness of disperse dyed polyester, cotton and P / C fabrics

\begin{tabular}{|c|c|c|c|c|c|c|}
\hline \multirow{2}{*}{ S. No. } & \multirow{2}{*}{$\begin{array}{l}\text { Concentration of } \\
\text { hydrophilic finish }(w / v)\end{array}$} & \multicolumn{5}{|c|}{$\mathrm{K} / \mathrm{S}$ value (610nm) } \\
\hline & & Polyester & PC 65 / 35 & $\mathrm{P} / \mathrm{C} 50 / 50$ & $\mathrm{P} / \mathrm{C} 35$ / 65 & Cotton \\
\hline 1 & 0 & $2-3$ & $2-3$ & $2-3$ & 2 & 1 \\
\hline 2 & 0.5 & 3 & $2-3$ & $2-3$ & 2 & 1 \\
\hline 3 & 1.0 & 3 & $2-3$ & $2-3$ & 2 & 1 \\
\hline 4 & 1.5 & 3 & $2-3$ & $2-3$ & 2 & $1-2$ \\
\hline 5 & 2.0 & 3 & $2-3$ & $2-3$ & 2 & $1-2$ \\
\hline 6 & 2.5 & 3 & $2-3$ & $2-3$ & 2 & $1-2$ \\
\hline
\end{tabular}

\subsection{Rubbing Fastness on Dyed Polyester, Cotton and P / C Fabrics}

The data of rubbing fastness properties of the dyed (basic dye, reactive dye and disperse dye) hydrophilic finished sodium hydroxide treated fabrics (P / C blend fabrics, $100 \%$ cotton \& PET fabrics) are given in the Tables 4-a, 4-b and 4-c respectively. It is evident from these tables that the rubbing fastness of reactive dyed and basic dyed cotton fabrics and its blend with polyester of more cotton proportion gives more rubbing fastness followed by disperse dyed fabrics. The disperse dyed polyester fabric shows satisfied rubbing fastness values (2) followed by the corresponding polyester/cotton blended fabric (1-2). The reactive dyed and basic dyed polyester fabrics as well as the disperse dyed cotton fabric only show very poor rubbing fastness properties (1 \& 1-2). There is a good improvement in the rubbing fastness properties of the blended fabric when dyed with basic dye, reactive dye, and disperse dye respectively. The sodium hydroxide treatment and hydrophilic finishing on polyester and its blend give considerable improvement in the rubbing fastness properties in continuation of their good dyeing.

Table 4-a. Rubbing fastness of basic dyed polyester, cotton and P / C fabrics

\begin{tabular}{llllll}
\hline \multirow{2}{*}{ S. No. } & $\begin{array}{l}\text { Concentration of } \\
\text { hydrophilic finish (w/v) }\end{array}$ & Kolyester & PC 65 / 35 & P/C 50 / 50 & P/C 35 / 65 \\
\cline { 3 - 6 } & 0 & 1 & 2 & 2 & $2-3$ \\
2 & 0.5 & 1 & 2 & 2 & 3 \\
2 & 1.0 & $1-2$ & 2 & 2 & 3 \\
3 & 1.5 & $1-2$ & 2 & 2 & $2-3$ \\
4 & 2.0 & $1-2$ & 2 & $2-3$ & 3 \\
5 & 2.5 & $1-2$ & $2-3$ & $2-3$ & 3 \\
6 & & & & $3-3$ & 3 \\
\hline
\end{tabular}

Table 4-b. Rubbing fastness of reactive dyed polyester, cotton and P/C fabrics

\begin{tabular}{|c|c|c|c|c|c|c|}
\hline \multirow{2}{*}{ S. No. } & \multirow{2}{*}{$\begin{array}{l}\text { Concentration of } \\
\text { hydrophilic finish }(w / v)\end{array}$} & \multicolumn{5}{|c|}{$\mathrm{K} / \mathrm{S}$ value $(530 \mathrm{~nm})$} \\
\hline & & Polyester & PC $65 / 35$ & $\mathrm{P} / \mathrm{C} 50$ / 50 & $\mathrm{P} / \mathrm{C} 35$ / 65 & Cotton \\
\hline 1 & 0 & 1 & 2 & 2 & $2-3$ & 3 \\
\hline 2 & 0.5 & 1 & 2 & 2 & $2-3$ & 3 \\
\hline 3 & 1.0 & $1-2$ & 2 & 2 & $2-3$ & $3-4$ \\
\hline 4 & 1.5 & $1-2$ & 2 & $2-3$ & 3 & $3-4$ \\
\hline 5 & 2.0 & $1-2$ & $2-3$ & $2-3$ & 3 & $3-4$ \\
\hline 6 & 2.5 & 2 & $2-3$ & $2-3$ & 3 & $3-4$ \\
\hline
\end{tabular}

Table 4-c. Rubbing fastness of disperse dyed polyester, cotton and P/C fabrics

\begin{tabular}{llllll}
\hline \multirow{2}{*}{ S. No. } & $\begin{array}{l}\text { Concentration of } \\
\text { hydrophilic finish (w/v) }\end{array}$ & Kolyester & PC 65 / 35 & P/C 50 / 50 & P/C 35 / 65 \\
\cline { 3 - 6 } & 0 & 2 & 2 & $1-2$ & $1-2$ \\
\hline 1 & 0.5 & 2 & 2 & $1-2$ & $1-2$ \\
2 & 1.0 & 2 & 2 & $1-2$ & $1-2$ \\
3 & 1.5 & 2 & 2 & $1-2$ & $1-2$ \\
4 & 2.0 & 2 & 2 & $1-2$ & 1 \\
5 & 2.5 & 2 & 2 & $1-2$ & 1 \\
6 & & 2 & $1-2$ & 1 \\
\hline
\end{tabular}




\subsection{Wetting Behavior of Hydrophilic Finished Sodium Hydroxide Treated Polyester, Cotton and P / C Fabrics}

The values of the wetting behaviour of sodium hydroxide (4\% owm) treated and hydrophilic finished $(0.5 \%, 1.0 \%$, $1.5 \%, 2 \%$ and $2.5 \%(\mathrm{w} / \mathrm{v}))$ fabrics $(100 \%$ polyester, $\mathrm{P} / \mathrm{C}$ 65 / 35; P / C 50 / 50; \& P / C 35 / 65 and 100\% cotton) are given in Table 5 . The sodium hydroxide treated and hydrophilic finished cotton fabrics show very good wettability compared with similar P / C 65 / 35; P / C 50 / 50; \& P / C 35 / 65 and 100\% polyester fabrics. The wettability of $100 \%$ polyester fabric is comparatively negligible; however, when blended with cotton in different proportions (P / C 65 / 35; P / C 50 / 50; \& P / C 35 / 65) and treated with sodium hydroxide followed by hydrophilic finishing the wettability is significantly increased. The sodium hydroxide treated fabrics $(100 \%$ polyester, $\mathrm{P} / \mathrm{C}$ blended fabrics and $100 \%$ cotton) when applied by hydrophilic finishing $(0.5 \%$, $1.0 \%, 1.5 \%, 2 \%$ and $2.5 \%(\mathrm{w} / \mathrm{v})$ show uniform progress in the wettability. There is a remarkable increase in the wetting behaviour of sodium hydroxide treated $\mathrm{P} / \mathrm{C}$ blend fabrics when applied with hydrophilic finish $(0.5 \%, 1.0 \%, 1.5 \%, 2 \%$ and $2.5 \%(\mathrm{w} / \mathrm{v})$ which is considerable up to the concentration of $2 \%$ owm, afterwards the increase is only marginal. Among the three P / C blend fabrics the wettability of P / C 35 / 65 tops the list followed by P / C 50 / 50 and P / C 65 / 35 respectively.

Table 5. Wetting behavior of hydrophilic finished sodium hydroxide treated polyester, cotton and P / C fabrics

\begin{tabular}{|c|c|c|c|c|c|c|}
\hline \multirow{2}{*}{ S. No. } & \multirow{2}{*}{$\begin{array}{l}\text { Concentration of } \\
\text { hydrophilic finish }(w / v)\end{array}$} & \multicolumn{5}{|c|}{ Wettability (sec) } \\
\hline & & Polyester & PC 65 / 35 & $\mathrm{P} / \mathrm{C} \mathbf{5 0} / \mathbf{5 0}$ & $P / C 35 / 65$ & Cotton \\
\hline 1 & 0 & 472 & 168 & 74 & 38 & 06 \\
\hline 2 & 0.5 & 151 & 128 & 66 & 34 & 05 \\
\hline 3 & 1.0 & 136 & 92 & 57 & 25 & 04 \\
\hline 4 & 1.5 & 112 & 71 & 47 & 19 & 03 \\
\hline 5 & 2.0 & 98 & 64 & 41 & 13 & 02 \\
\hline
\end{tabular}

\subsection{Water Retention in Hydrophilic Finished Sodium} Hydroxide Treated Polyester, Cotton and P / C Fabrics

The data of water retention of sodium hydroxide (4\% owm) treated and hydrophilic finished $(0.5 \%, 1.0 \%, 1.5 \%, 2 \%$ and $2.5 \%(\mathrm{w} / \mathrm{v}))$ fabrics (100\% polyester, P / C $65 / 35 ; \mathrm{P} / \mathrm{C}$ 50 / 50; \& P / C 35 / 65 and 100\% cotton) are given in Table 6. The water retention behaviour is maximum for cotton fabric (sodium hydroxide treated and hydrophilic finished) followed by similar P / C blend fabrics and the value is very low for $100 \%$ polyester fabrics. When the sodium hydroxide treated fabrics (100\% polyester, P / C 65 / 35; P / C 50 / 50; \& P / C $35 / 65$ and 100\% cotton) are processed with hydrophilic finish $(0.5 \%, 1.0 \%, 1.5 \%, 2 \%$ and $2.5 \%(\mathrm{w} / \mathrm{v})$ there is a significant increase in the values of water retention of these fabrics. The concentration of hydrophilic finish gives the influences upto the concentration of $2 \% \mathrm{w} / \mathrm{v}$; when the concentration is increased beyond this value there is only marginal increase in the water retention behaviour in all these materials. Next to cotton fabric the P / C blend 35 / 65 fabric gives the high water retention values followed by P / C 50 / 50 and P / C 65 / 35 fabrics respectively. Similarly there is a remarkable increase in the water retention values of sodium hydroxide treated $100 \%$ PET fabrics when applied with hydrophilic finish up to the concentration of $2.0 \% \mathrm{w} / \mathrm{v}$, afterwards the increase is only marginal.

Table 6. Water retention in hydrophilic finished sodium hydroxide treated polyester, cotton and $P$ / C fabrics

\begin{tabular}{|c|c|c|c|c|c|c|}
\hline \multirow{2}{*}{ S. No. } & \multirow{2}{*}{$\begin{array}{l}\text { Concentration of } \\
\text { hydrophilic finish }(w / v)\end{array}$} & \multicolumn{5}{|c|}{ Water retention $(\%)$} \\
\hline & & Polyester & PC $65 / 35$ & $\mathrm{P} / \mathrm{C} 50$ / 50 & P/C 35 / 65 & Cotton \\
\hline 1 & 0 & 144 & 238 & 265 & 294 & 378 \\
\hline 2 & 0.5 & 148 & 249 & 282 & 313 & 396 \\
\hline 3 & 1.0 & 157 & 264 & 297 & 326 & 408 \\
\hline 4 & 1.5 & 171 & 278 & 311 & 342 & 421 \\
\hline 5 & 2.0 & 184 & 291 & 315 & 354 & 433 \\
\hline
\end{tabular}

\subsection{Wicking Behaviour of Hydrophilic Finished Sodium Hydroxide Treated Polyester, Cotton and P / C Fabrics}

The wicking behaviour of sodium hydroxide (4\% owm) treated and hydrophilic finished $(0.5 \%, 1.0 \%, 1.5 \%, 2 \%$ and $2.5 \%(\mathrm{w} / \mathrm{v}))$ fabrics (100\% polyester, P / C 65 / 35; P / C $50 / 50$; \& P / C $35 / 65$ and $100 \%$ cotton) is given in the Table 7. From this table it is clearly seen that after the sodium hydroxide treatment and hydrophilic finish, there is a very good wicking behaviour exhibited by these fabrics. After the hydrophilic finish the sodium hydroxide treated polyester fabric shows subsequent rate of increase in the wicking behaviour compared to the similar cotton fabric. As expected the values of wicking are considerably increased in the sodium hydroxide treated and hydrophilic finished $\mathrm{P} / \mathrm{C}$ blend fabrics. The P / C 35 / 65 blend fabrics (sodium 
hydroxide treated and hydrophilic finished) show very good wicking behaviour next to the corresponding cotton fabric which is in the top list among all the fabrics (Table 7). The behaviour of wicking is directly proportional to the behaviour of the textiles containing hydrophilic groups in their polymers $[6,23,24]$, accordingly when the fabrics are treated with sodium hydroxide and subsequently hydrophilic finished the wicking behaviour is also respectively increased as evidenced in the Table 7 .

Table 7. Wicking behaviour of hydrophilic finished sodium hydroxide treated polyester, cotton and P / C fabrics

\begin{tabular}{|c|c|c|c|c|c|c|}
\hline \multirow{2}{*}{ S. No. } & \multirow{2}{*}{$\begin{array}{l}\text { Concentration of } \\
\text { hydrophilic finish }(w / v)\end{array}$} & \multicolumn{5}{|c|}{ Wicking (cm) [for 45 minutes] } \\
\hline & & Polyester & PC 65 / 35 & $\mathrm{P} / \mathrm{C} 50 / 50$ & $\mathrm{P} / \mathrm{C} 35$ / 65 & Cotton \\
\hline 1 & 0 & 6.5 & 7.8 & 8.7 & 10.2 & 14.5 \\
\hline 2 & 0.5 & 6.8 & 8.6 & 9.8 & 11.6 & 15.2 \\
\hline 3 & 1.0 & 7.3 & 9.7 & 10.5 & 13.4 & 16.0 \\
\hline 4 & 1.5 & 7.9 & 10.5 & 11.8 & 14.7 & 16.4 \\
\hline 5 & 2.0 & 8.8 & 11.4 & 12.7 & 15.9 & 17.7 \\
\hline 6 & 2.5 & 9.0 & 11.7 & 13.0 & 16.3 & 17.9 \\
\hline
\end{tabular}

\subsection{Measurement of Static Charge on Polyester, Cotton and $P$ / C Fabrics}

The untreated PET fabric showed a static charge of $0.1 \mathrm{KV}$ whereas the sodium hydroxide $(4 \%$ owm $)$ treated and hydrophilic finished $(0.5 \%, 1.0 \%, 1.5 \%, 2 \%$ and $2.5 \%$ (w/v) ) fabrics (100\% polyester, P / C 65 / 35; P / C 50 / 50; \& P / C 35 / 65 and 100\% cotton) showed static charge less than $0.1 \mathrm{KV}$. Static electricity refers to the built up of electric charge on the surface of objects. Polyester fiber is easy to accumulate static charge because of its hydrophobic character The sodium hydroxide treated and hydrophilic finished fabrics contain hydroxyl groups and carboxyl groups that enhance the electronic conductivity of the samples, thereby show reduced static charge value.

\section{Conclusions}

The k/s values for basic, reactive, and disperse dyes are good when dyed on cotton and polyester fabrics respectively. There is a good improvement in $\mathrm{k} / \mathrm{s}$ value for the sodium hydroxide treated and hydrophilic finished PET blended fabrics.

The wash, light and rubbing fastness properties of sodium hydroxide (4\% owm) treated and hydrophilic finished $(0.5 \%$, $1.0 \%, 1.5 \%, 2 \%$ and $2.5 \%(\mathrm{w} / \mathrm{v}))$ fabrics $(100 \%$ polyester, P / C 65 / 35; P / C 50 / 50; \& P / C 35 / 65 and 100\% cotton) are good and significant correspondingly with respect to their $\mathrm{k} / \mathrm{s}$ values.

The wetting behaviour on sodium hydroxide treated P / C blend fabric is enhanced significantly after the application of hydrophilic finish chemicals.

The water retention character on sodium hydroxide treated $\mathrm{P} / \mathrm{C}$ blend fabric is highly increased after the hydrophilic finish up to the concentration of $2.0 \% \mathrm{w} / \mathrm{v}$. After $2.0 \% \mathrm{w} / \mathrm{v}$ concentration of hydrophilic finish chemicals, the increase is very marginal.

There is a uniform increase of wickability in the sodium hydroxide treated $\mathrm{P} / \mathrm{C}$ blend fabric after hydrophilic finish which is significant up to the concentration of $2.0 \% \mathrm{w} / \mathrm{v}$, after that the increase is very marginal. Also the static charge of sodium hydroxide and hydrophilic finished PET blend fabrics is less.

\section{Acknowledgements}

The authors kindly express their gratitude to Dr. R. Rudramurthy, Principal and the Head, Department of Applied Science, PSG College of Technology, Coimbatore 641004 for granting permission and support in publishing this research article.

\section{References}

[1] Rao, M.V.S. and Talele, A.B. A Guide to Crimping/Texturing Technology, MANTRA, Man Made Textiles Research Association, Surat, 1992.

[2] Jacobasch H.J., Baubock, G. and Schurz, J. "Problems and results of zeta potential measurements on fibers", Colloid. Polym. Sci., Vol. 263, No. 1, pp. 3-24, 1985.

[3] Latta, B.M. "Improved tactile and sorption properties of polyester fabrics through caustic treatment", Text. Res. J., Vol. 54, pp. 766-775, 1984.

[4] Prorokova, N. P., Khorev, A.V. and Vavilova, S.Y. "Chemical method of Surface Activation of Poly(thylene terephthalate) Fibre Materials", Fibre. Chem., Vol. 41, No. 3, pp. 158-163, 2009.

[5] Sanders, E.M. and Zeronian, S.H. "An analysis of moisture related properties of hydrolysed polyester", J. Appl. Polym. Sci., Vol. 27, pp. 4477-4491, 1982.

[6] Bal, S. and Behera, R.C. "Structural investigation of chemical treated polyester fibres using SAXS and other techniques", J. Miner. Mater. Charact. Eng., Vol. 5, No. 2, pp. 179-198, 2006.

[7] Kulshreshtha, A.K. Khan, A.H. and Madan,G.L. "X-ray diffraction study of solvent-induced crystallization in polyester filaments," Polymer, vol. 19, No. 7, pp. 819-823, 1978.

[8] Kish, M.H. and Nouri, M. "Effects of sodium hydroxide and calcium hydroxide on polyester fabrics", J. Appl. Polym. Sci., Vol. 72, pp. 631-637, 1999.

[9] Trotman E.R. 'Dyeing and Chemical Technology of Textile Fibers', $6^{\text {th }}$ edition, Edward Arnold, London, pp.187-217, 1984. 
[10] Cook J G, Handbook of Textile Fibres, Vol II, Man Made Fibres, Woodhead Publishing Limited,Cambridge, England, 2005.

[11] Oktem, T., Seventekin, N., Ayhan, H. and Piskin, E. "Modification of polyester and polyamide fabrics by different in situ plasma polymerisation methods", Turk. J. Chem., Vol. 24, No. 3, pp. 275-285, 2000.

[12] Shenai V.A. Technology of Dyeing, Sevak Publications, Mumbai, 1977.

[13] Peters, R.H. The Physical Chemistry of Dyeing, Elsevier Scientific Publications Company, 1975.

[14] BIS Test Method IS:764-1979, Test 3, "Indian Standard Method for Determination of Colour Fastness of Textile Materials to Washing", Bureau of Indian Standards, 1979.

[15] AATCC Test Method 16E-2004, "Colour Fastness to Light", Technical Manual of the AATCC, Research Triangle Park, U.S.A, 2004

[16] AATCC Test Method 8-2007, "Colour Fastness to Crocking", Technical Manual of the AATCC, Research Triangle Park, U.S.A, 2007.

[17] AATCC, Technical Manual, (1991), American Association of Textile Chemists and Colorists, Research Triangle Park,N.C. Vol. 66.
[18] AATCC, Technical Manual, (1979), American Association of Textile Chemists and Colorists, Research Triangle Park,N.C. Vol. 55.

[19] Tyagi, G.K. Krishna, G. Bhattacharya, S and Kumar, P. Indian J Fiber Text Res, Vol. 34, pp. 137-143, 2009.

[20] Swarna Natarajan, and Jeyakodi Moses, J. "Surface Modification of Polyester Fabric using Polyvinyl Alcohol in Alkaline Medium", Indian Journal of Fibre and Textile Research, Vol.37, pp. 287-291, 2012.

[21] Bell, V.A., Lewis, D.M. and Pailthorpe, M.T., "Wool Dyeing", edited by Lewis D M, Dyers', Company Publications Trust, 1992.

[22] Kish, M.H. and Nouri, M. "Effects of sodium hydroxide and calcium hydroxide on polyester fabrics", J. Appl. Polym. Sci., Vol. 72, pp. 631-637, 1999.

[23] Dave, J., Kumar, R. and Srivastava, H.C. "Studies on modification of polyester fabrics I: Alkaline hydrolysis", J. Appl. Polym. Sci., Vol. 33, pp. 455-477, 1987.

[24] Hsieh, Y.L., Miller, A. and Thompson, J. "Wetting, pore structure and liquid retention of hydrolysed polyester fabrics", Text. Res. J., Vol. 66, No. 1, pp. 1-10, 1996. 